\title{
A Study of Establishing A Conceptual Model for Understanding The Impact of Social Commerce on Consumer Decision Making With Social Support Perspective
}

\author{
Amal Wijenayaka \\ Girne American University \\ amalwijenayaka3@gmail.com \\ https://orcid.org/ \\ 0000-0002-3457-3304
}

\begin{abstract}
The introduction of social commerce ushered in a new era in business-consumer interaction. As a result, more power has passed from the vendor to the buyer, primarily fueling e-commerce acceptance. As a result, understanding consumer behaviour in the context of social commerce adoption has become essential for businesses looking to persuade customers by using the power of social ties and support.
\end{abstract}

Furthermore, such social ties will facilitate trust as the most promising benefit while reducing perceived risk, which has always been a critical problem with online commerce. This study proposes a paradigm for understanding the impact of social commerce on the stages of the consumer decision-making process: need recognition, information search, alternative evaluation, purchase decision, and post-purchase behaviour, with a focus on social support. In this respect, relevant literature in the subject of social commerce either (1) lacks an adequate explanatory model, (2) has a solid theoretical base, or (3) contains practically complex theories with insufficient empirical data.

The research model applies the Social Commerce Constructs (SCC): recommendations and referrals, forums and communities, and ratings and reviews to study the respective influence on the consumer decision-making process phases. This paper aims to understand the influence of social commerce on an integrative model that incorporates all customer choice phases while expecting new knowledge. Furthermore, it is advised that this conceptual model be empirically verified to evaluate the practical consequences.

Keywords: Decision Making Process, Social Support, Social Networks, Social Commerce, 


\subsection{Introduction}

It is self-evident that Web 2.0, most notably social networking sites, significantly impacts our online behaviour. Indeed, from a business standpoint, it has increased its influence on consumers' offline and online purchase decisions (Wang \& Yu, 2015; Hajli N., 2015). Social commerce and associated social media marketing have evolved and become fashionable. Subsequently, social media contributed to consolidation e-commerce implementation by establishing trust and reducing perceived risk, which was heavily impacted by the online community's social support. Furthermore, Web 2.0 social technologies and infrastructures are used in social commerce to allow interactions and user contributions in a digital context, supporting customers' product and service purchases (Liang \& Turban, 2011).

Notably, social media settings enable consumers to purchase items and services and collaborate with sellers to generate content that benefits both parties (Do-Hyung et al., 2007). As a result, consumers are increasingly becoming active content providers on the Internet, contrary to their previous passive behaviour (Hajli M.,2012). Moreover, social media is no longer considered a niche medium, as it has been extensively adopted and is being used to a greater level. social commerce's applicability is not segmented by demographic or geographic profile. Indeed, social commerce is a global phenomenon. As a result, companies and marketers should have no reservations about capitalizing on the assistances of social commerce. Thus, social commerce is no longer a novel concept and is expected to become the primary driving force of a company soon.

Additionally, consumer decisions will be heavily influenced by and inevitably influenced by social commerce, which is highly backed by online social support. Nonetheless, there is a scarcity of studies on the impact of SCC-facilitated Online Social Networks (OSN) on the stages of the consumer decision-making process: need recognition, information search, alternative appraisal, purchase choice, and post-purchase behaviour.

This article proposes a framework for analyzing the impact of social commerce on the stages of the consumer decision-making process, with a particular emphasis on the social support perspective, because existing literature in the field of social commerce either (1) lacks an adequate explanatory model or (2) lacks a substantial theoretical foundation. The suggested research model examines the influence of the SCCs: recommendations and referrals, forums and 
communities, and ratings and reviews on the various stages of the consumer decision-making process. Zhang and Benyoucef (2016) asserted a theoretical and empirical gap in studying the phenomenon mentioned above, as existing literature has primarily focused on the impact of social commerce on individual stages or subsets of stages, rather than on the holistic consumer decision-making process stages.

Furthermore, the study's specific empirical findings will aid companies in developing efficient social commerce strategies for their brands that will benefit them at every stage of the decisionmaking process. As a result, social commerce as an extension of the e-commerce paradigm may be optimized shortly. As a result, the remainder of the concept paper is organized as follows. To build the model's research propositions, the second section examines the theoretical underpinnings of social commerce, online social support, and consumer decision-making process phases; the third section describes the resulting conceptual model. Finally, the article's intended repercussions are addressed in the fourth section, which brings the work to a close..

\subsection{Literature review}

\subsection{Social commerce}

In general, OSNs (which are frequently grouped under the umbrella term "Social Media" or "Web 2.0") are web-based services that enable users to create profiles and connect with other users within the same system, allowing them to view and navigate among themselves (Boyd \& Ellison, 2007; Kaplan \& Haenlein, 2010). Notably, such OSNs enable communities of individuals to connect online and exchange information, expertise, and perspectives (Kaplan $\&$ Haenlein, 2010). OSNs, notably Facebook, have gained widespread acceptance and adoption among the world's Internet users. Around 2 billion Internet users utilize OSNs, and these figures are likely to continue growing as the use of intelligent mobile devices and Internet accessibility spreads (Statista, 2016). Additionally, social media consumption makes for the largest share of Internet consumption activity. For example, the average time spent on Facebook per visit is roughly 18 minutes internationally (Statistic Brain, 2016).

Social commerce uses Web 2.0 social technology and facilities to facilitate interrelations and user contributions in an online environment, thereby assisting consumers in their product and service acquisition (Liang \& Turban, 2011). Compared to traditional business, commerce, and 
marketing, these OSNs (mainly Facebook, which has revolutionized the landscape of business, commerce, and marketing) enable the consumer to be more descriptive and interactive (see Song \& Yoo, 2016; Wang \& Yu, 2015). Indeed, such OSN channels, such as Facebook, empowered consumers to play a more active role in the market by enabling them to reach (and be reached by) anyone, anywhere, and at any time (Hennig-Thurau et al., 2010). Now, regardless of the size of the business, most businesses readily admit that social media is an integral part of their marketing strategy. As a result, it is recommended that businesses establish a presence on social media platforms (Osei \& Abenyin, 2016; Heinrichs et al., 2011).

\subsection{Social commerce and Social support}

A business strategy tailored to social commerce is critical for an organization, as the next generation of online consumers are backed mainly by communities (Ridings \& Gefen, 2004). Also, unlike in the past, where the social impact was limited to a narrow social group, the user experience online is much different from offline. Social support is defined as an individual's experience of being cared for, reacted to, and supported by others as a social group member (Cobb, 1976; Ali, 2011). The literature confirms that social support, both offline and online, significantly impacts consumer behaviour. Li (2008) argued that user behaviour is influenced by their own and other users in their OSN. Thus, social interaction and social support theories will be relevant in social commerce research (Liang \& Turban, 2011). Socio-commercial activities (i.e. social interactions and user-generated content) are combined in a Web 2.0 context (Liang \& Turban, 2011). Social technology enables people to connect with family, friends, peers, other communities, and vendors. OSNs allow users to access and monitor decisions and views about products and services made by people worldwide (Wang \& Yu, 2015; Pan et al., 2007). Hajli (2015) proposes that OSN members share their consumption experiences via SCCs (rating and reviewing, recommending and referral, and forums and communities). They provide informational and emotional support to each other (Liang et al., 2011; Hajli N., 2013). An essential role for SCCs is emotional and informational support (Mohana et al.). The social aspect of social commerce sets it apart from traditional commerce and other online economic activity. For this reason, social support is a crucial factor of consumer social commerce intention and success (Liang et al., 2011). the study of social commerce (Liang et al., 2011; Zhang et al. 2014). 
SCCs are social elements of Web 2.0 that allow users to create content and share their experiences (Hajli N., 2015). Members of online communities participate in various group activities and support one another through social interactions and communications, all of which influence consumer behaviour (Bagozzi \& Dholakia, 2002; Ridings \& Gefen, 2004). The major enablers of social support in OSNs include SCCs, such as rating and reviews, recommendations and referrals, and forums and communities (Hajli N., 2013). Furthermore, Hajli et al. (2014) emphasized that SCCs are produced by conceptualizing eWOM (electronic word of mouth), also known as User Generated Content (UGC) in social commerce. SCCs in OSNs let customers see how community members perceive and react to products and services through user-generated content (UGC). The nature of SCCs can be good or bad for a product or service, depending on the consumers' experience and level of satisfaction. As a result, SCCs supply material that may attract and retain customers and disturb and switch customers. Consumers can vote on items and services using ratings. Ratings do encourage more involvement because they require less work from the consumer. Consumers can provide feedback on items and services through reviews. Consumers can explain their experience in reviews, which are longer. Recommendations and referrals are individualized endorsements of a product or service from the recipient's social network.

On the other hand, ratings and reviews are visible to anybody who wants to see them. Moreover, through forums and communities, consumers can participate in group discussions and share information in a specialized community group or forum within the OSN. Importantly, these SCCs' availability and functionalities are dependent on the platform (i.e., online social network platform).

Significantly, the social support facilitated in social commerce increased customer trust and reduced perceived risk, resulting in increased purchasing intent (Hajli N., 2015; Han \& Windsor, 2011). Consumer trust is the most challenging issue in e-commerce, which social commerce may help with. Consumers seek product, service, and company information in OSNs because they believe such sites provide UGC that is more reliable and relevant than information provided by marketers (Fotis et al., 2012; Bernoff \& Li, 2008) and traditional media (Fotis et al., 2012; Bernoff \& Li, 2008). (Goh et al., 2013). Furthermore, SCCs give an incentive for sellers to be trustworthy (Hajli N., 2013). Furthermore, people are more likely to consider and follow others' 
heuristic information (i.e., choices, opinions, and so on) to reduce the cognitive effort in decision making and overcome information overload (Bonabeau, 2004; Simpson et al., 2008), which could be added to a greater extent by OSNs. When purchasing online, consumers have no experience physically inspecting (i.e. touching, smelling, etc.). Other consumers' comments, reviews, and ratings, on the other hand, can alleviate these restrictions and impact consumer behaviour (Do-Hyung et al., 2007; Akar \& Topçu, 2011). Consumers appear to be more interested in other people's recommendations than information supplied by vendors (Ridings \& Gefen, 2004). As a result, Senecal and Nantel (2004) claimed that online recommendations heavily impact consumers' online purchase decisions. As a result, consumers may rely on such online suggestions, mainly if they cannot try out the products or services in an online setting. Furthermore, as the quality of the reviews and the number of online reviews improve, consumers' likelihood of making a purchase (DoHyung et al., 2007). Third-party reviews, in reality, have a substantial influence on customer purchasing decisions (Yubo \& Jinhong, 2005). Furthermore, Cheung et al. (2014) found that an increase in the total number of ratings on a product or service beneficial impacts consumer purchasing decisions. They also emphasized that earlier purchase information provided by other customers on an ONS can serve as a reference point for subsequent purchasing decisions made by the same consumer and later potential consumers.

\subsection{Social commerce and decision making}

Consumer behaviour attempts to comprehend the consumer decision-making process, which consists of numerous stages, including the primary act of purchasing things and services.

Numerous researchers and academics have established and changed consumer decision-making process models based on various aspects and conclusions. There was some disagreement among scholars regarding the consumer decision-making process model (e.g., Nicosia, 1966; Engel, Kollat, \& Blackwell, 1968; Rice, 1993; Tyagi \& Kumar, 2004; Foxall, 2005). However, the fivestage model, which explains five critical activities in the consumer decision-making process: need recognition, information search, alternative evaluation, purchase decision, and postpurchase behaviour (e.g., Kotler \& Armstrong, 2016; Kotler \& Keller, 2016; Schiffman \& Wisenblit, 2015), is widely accepted. It is widely understood that marketers must consider all stages of the consumer decision-making process rather than focusing exclusively on the purchase decision stage. 
While each stage marks a critical decision point in the decision-making process, not all consumers pursue them sequentially (Kotler \& Armstrong, 2016; Osei \& Abenyin, 2016; Rad \& Benyoucef, 2011). Moreover, while customers go through all five stages with each purchase, they frequently skip or reverse parts of these steps on more typical purchases (Kotler \& Armstrong, 2016).

Consumer behaviour analysis has been an intriguing research topic in traditional and online marketplaces. For example, social media can influence the rationality and effectiveness of consumer choice-making in both positive and wrong ways (Wang \& Yu, 2015; Rad \& Benyoucef, 2011; Power \& Phillips-Wren, 2011). Additionally, customers tend to place a higher premium on negative eWOM than on good eWOM when purchasing decisions (Park \& Lee, 2009).

The majority of social commerce research has focused on consumer behaviour by examining information-seeking behaviour (particularly eWOM) (e.g., Bilgihan et al., 2014; Bronner \& Hoog, 2014; Chu \& Choi, 2011), purchase attitude, and purchase intention (e.g., Hajli N., 2015; Ng, 2013; Wang \& Chang, 2013; Wang et al., 2012). However, Yadav et al. (2013) stated that the social commerce domain should not be defined simply in terms of consumer behaviour's purchasing function but rather should comprise exchange-related behaviours that occur prior to, during, and after a focal transaction. As a result, Yadav et al. (2013) defined social commerce as "exchange-related activities that take place within or are influenced by an individual's social network in computer-mediated social environments, where the activities correspond to the need recognition, pre-purchase, purchase, and post-purchase stages of a focal exchange." Additionally, Osei and Abenyin (2016) and Zhang and Benyoucef (2016) established the validity of applying the consumer decision-making process stages model to examine the impact of social commerce on consumer decision-making. Numerous experts have claimed that creating a compelling consumer experience that completely integrates social interactions into every level of the consumer decision-making process is a prerequisite for successful social commerce (e.g., Yadav et al., 2013; Huang \& Benyoucef, 2013; Zhou et al., 2013).

\subsubsection{Social commerce and problem recognition}

Consumer need recognition (problem recognition) arose as a result of the disparity between the consumer's current and desired state of affairs. The requirement is primarily triggered by internal 
or external stimuli (Kotler \& Armstrong, 2016). According to the literature on social learning theory, the social environment has a significant influence on and determination of perceived needs (Bandura, 1977). Thus, individuals gain knowledge about a product or service by observing others, which prompts them to adopt the same product or service. The OSNs can motivate consumers' needs and desires ( $\operatorname{Rad} \&$ Benyoucef, 2011).

OSNs enable consumers to be regularly informed and observed about the activities of their members, including information about specific products and services. Indeed, OSNs serve as a catalyst for consumers to become aware of a problem or need through inspiration and referrals (Yadav et al., 2013). Furthermore, Cox and Park (2014) established that SCCs (e.g., Likes and Recommendations) in OSNs can attract the consumer (i.e., his/her need recognition).

\subsubsection{Social commerce and information search}

When someone is interested in a product or service, they are likely to look for more information.

Consumers can get knowledge from various sources, including personal, commercial, public, and experiential sources. Personal sources, in particular, have a significant impact on consumer behaviour since they are seen to be more trustworthy (Kotler \& Armstrong, 2016). Specifically, word of mouth is one of the most appealing sources of information as a personal source that aids in consumer decisions.

The changing role of the Internet has increased the number of customers who use various Internet resources, including OSNs, to find information. Among the various responsibilities, OSNs play a unique role as an expanded personal information source (enabling users to connect with family members, friends, acquaintances, neighbours, and others in OSNs), which is primarily driven by eWOM as a result of social interaction. OSNs serve as a source of information for consumers, allowing them to conduct searches (Yadav et al., 2013). With the introduction of OSNs, customers' ability to communicate and exchange information has expanded and improved. Furthermore, OSNs may have reduced the cost of searching. In OSNs, consumers have a wide range of options and the freedom to actively voice their ideas and information about the products and services (Hennig-Thurau et al., 2010). According to Xiang and Gretzel (2010), OSNs allow consumers to share information, including personal consumption-related experiences, with other members in a connected manner, and so such OSNs 
can be considered powerful information sources for consumers. Furthermore, members of online social networks are likely to trust the information and perspectives of their connections (Power \& Phillips-Wren, 2011; Chu \& Kim, 2011; Rad \& Benyoucef, 2011).

Indeed, user-generated content (UGC) is more trustworthy and relevant than material provided by marketers (Fotis et al., 2012; Bernoff \& Li, 2008) or traditional media (Goh et al., 2013).

\subsubsection{Social commerce and alternative evaluation}

Consumers, on the whole, examine all available information in order to evaluate numerous alternative products or services and compare them to their respective needs and wants (Kotler \& Armstrong, 2016).

OSNs serve as a resource for consumers to compare and contrast options (Yadav et al., 2013).Consumers will be able to analyze and choose their favourite brand based on information available on OSNs. Among the various information sources available within OSNs, UGC from personal sources has a significant impact on consumer decisions since such sources are viewed as trustworthy and enable consumers to evaluate items or services (Kotler \& Armstrong, 2016). Because customers may access the reviews, ratings, and suggestions of other members of the same community (Wang \& Yu, 2015; Hennig-Thurau et al., 2012; Rad \& Benyoucef, 2011), OSNs have a substantial impact in the pre-purchase phase, including the alternative evaluation stage. Furthermore, when such SCCs come from unknown and anonymous customers, they significantly impact the consumers' perception of risk (Hennig-Thurau et al., 2012). Consumergenerated material is more trustworthy than marketer-generated content at the end (Bae \& Lee, 2011).

\subsubsection{Social commerce and purchase decision}

Following the formation of a buying intention, consumers purchase the most preferred goods or services. It is not always the case that a preference or even a purchasing intention leads to a purchase decision (Kotler \& Armstrong, 2016). However, purchase intent is a psychological component that can influence actual purchasing behaviour (Wang \& Yu, 2015).

Consumers make critical decisions at this stage, such as which retailer to buy from when to buy from, and other terms and circumstances associated with the transaction, as well as the exact 
product or service to buy. OSNs serve as a source of information for customers, allowing them to decide what to buy, where to buy it, and when to buy it (Yadav et al., 2013). Wang \& Yu (2015) found that OSNs' social contacts and support considerably impact deliberate and accurate purchasing decisions (Hajli N., 2013; Rad \& Benyoucef, 2011; Han \& Windsor, 2011). Similarly, Stephen and Galak (2012) found that socially earned media activities had a more significant impact on sales than traditional earned media. Furthermore, these earned social media efforts have a long-term impact on sales. According to Wang and Yu (2015), purchasing information shared by other OSN members can be a powerful referral for later consumer purchasing decisions. Yadav et al. (2013) found that SCCs in OSNs can give helpful information that reduces perceived effort and increases the likelihood of making a better buying decision.

\subsubsection{Social commerce and post-purchase behaviour}

Consumers engage in post-purchase behaviour after making a purchase, primarily dependent on their level of satisfaction (Kotler \& Armstrong, 2016).

The difference between consumer expectations and perceived product or service performance will influence consumer happiness. When the gap is small, the customer is more satisfied. (Kotler \& Armstrong, 2016) Customer happiness is the key to building lucrative connections. Satisfied customers are more likely to make repeat purchases, recommend the products and services to others, and pay less attention to competitors' branding and promotions, resulting in brand loyalty.

Furthermore, happy customers are more likely to buy other items and services from the same company. Unsatisfied customers react differently, with negative word of mouth spreading faster and farther than positive word of mouth, damaging customer perceptions of products and services. Social contacts in OSNs occur more frequently and with more intensity than traditional exchanges. As a result, post-purchase activities are more common in OSNs. In reality, OSNs serve as a platform for sharing consumer delight and experience. Consumers frequently compare their actual consumption experience with their expectations after making a purchase. Consumers can then use the SCCs to convey their degree of pleasure to other consumers via OSNs (HennigThurau et al., 2004). 
Furthermore, consumers can recommend and assist others in the OSNs, according to Yadav et al. (2013). According to Liang et al. (2011), social support has a beneficial impact on the intention to utilize social commerce in the future, and better social support could increase consumer loyalty. Consumer motivations that OSNs can support include validating an opinion, assisting or educating others, sharing, bonding, and showing pride related to a particular purchase (Yadav et al., 2013). In addition, the chance of post-purchase behaviours (feedback, reviews, etc.) in OSNs is significantly increased by social interactions (Wang \& Yu, 2015).

\section{Propositions from the literature review}

H1:SCCs have a positive impact on the Need Recognition stage of the consumer decision making

H2:SCCs have a positive impact on the Information Search stage of consumer decision making

H3:SCCs have a positive impact on the Alternative Evaluation stage of consumer decision making

H4:SCCs have a positive impact on the Purchase Decision stage of consumer decision making H5:SCCs have a positive impact on the Post-Purchase Behavior stage of consumer decision making

\section{Conceptual Framework}

This study uses Yadav et al. (2013)'s concept of social commerce since it encompasses all stages of the customer decision-making process, including purchasing behaviour. Indeed, it has broadened the scope of social commerce, allowing firms to measure their marketing potential in terms of the influence of social support. As a result, this research article constructs a model (see Figure 01) to address the impact of social commerce on the stages of the consumer decisionmaking process from the standpoint of social support.

According to Hajli N. (2013), the study's independent variable is SCCs, which include three dimensions: referrals and recommendations, forums and communities, and review and rating. According to Yadav et al. (2013), the study's dependent variables are stages of the consumer decision-making process: need recognition, information search, alternative appraisal, buy choice, 
and post-purchase behaviour. The identified research propositions (Figure 01) are built to evaluate the impact of SCCs on each stage of the consumer decision-making process.

Figure 01

Conceptual Framework

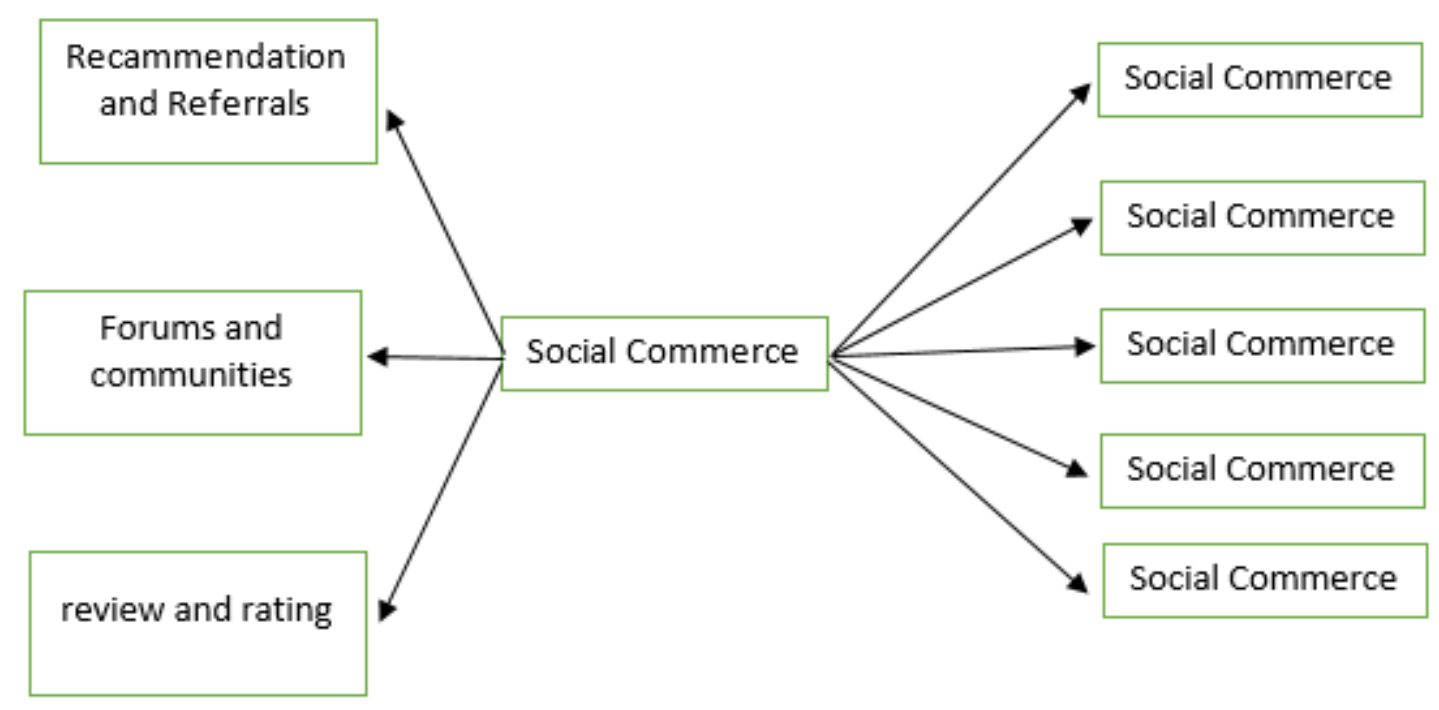

\section{Conclusion}

Due to the novelty of the phenomenon, there are insufficient theoretical models and empirical evidence in the field of consumer behaviour in social commerce, which this model development article aimed to solve. Zhang \& Benyoucef, 2016; Liang \& Turban, 2011) acknowledged that, among other relevant topics, this could be the most attractive study field soon (e.g., Zhang \& Benyoucef, 2016; Liang \& Turban, 2011). This paper uses Yadav et al. (2013) .'s definition of social commerce and focuses the discussion on OSN sites emphasizing the "social" aspect of social commerce, in line with Zhang and Benyoucef's thesis (2016). According to the available literature, there is a lack of a systematic framework followed by empirical research that analyzes the few stages, resulting in an inadequate picture of the function of social commerce in decision- 
making processes. The effects of social commerce on consumer decision-making process phases, as stated by Yadav et al. (2013), are worth researching for enterprises to harness.

This research aims to understand the impact of social commerce on each step of the consumer decision-making process without considering the interconnectedness of the phases. Due to the novelty of the research topic and the lack of literature with empirical evidence in the context of social commerce, the researchers believe that such inter-relatedness could not be determined. Furthermore, some customers may use social commerce for only a portion of their decisionmaking process. Song \& Yoo, 2016; Wang \& Yu, 2015; Hajli N., 2015; Liang et al., 2011) are examples of literature with empirical data for examining independent and dependent variable connections individually assuming stages of the decision-making process. As a result, if the literature evaluates dependent variables separately, there is a strong case for combining all decision processes into a single study. As a result, this study aims to understand the influence of social commerce in order to develop an integrated model that incorporates all decision phases while expecting new insights. However, academics contend that the interconnectedness of the stages of the decision-making process is beyond the scope of this study. Understanding the importance of social commerce in consumer behaviour helps marketers enhance their campaigns and better understand their customers.

Furthermore, such knowledge directly impacts the company's overall success. Furthermore, firms must successfully manage online social platforms because they considerably impact customer decisions. Therefore, it is also crucial to figure out how social commerce fueled by social support affects various stages of the consumer decision-making process. SCCs with a positive influence on the consumer decision-making process stages will help brands thrive in the market; similarly, SCCs with a negative impact on any stage of the consumer decision-making process should be considered harmful. Furthermore, such a negative impact is predicted to grow with time in online social communities that rely on eWOM, and it will almost probably have a negative impact at subsequent phases. As a result, potential customers will flee the seller's clutches, and current customers will quickly switch to competitors.

To be validated, this study model must be empirically examined, and it may be expanded in the future. 
Furthermore, this framework is limited to the social support perspective of social commerce; however, future research is needed to develop a comprehensive model that includes other aspects of social commerce to explore the impact on the phases of the consumer decision-making process.

\section{Reference}

Akar, E., \& Topçu, B. (2011). An Examination of the Factors Influencing Consumers' Attitudes Toward Social Media Marketing. Journal of Internet Commerce, 10(1), 35-67.

Ali, H. (2011). Exchanging value within individuals' networks: Social support implications for health marketers. Journal of Marketing Management, 27(3- 4), 316-335.

Bae, S., \& Lee, T. (2011). Product Type and Consumers' Perception of Online Consumer Reviews. Electronic Markets, 21(4), 255-266.

Bagozzi, R. P., \& Dholakia, U. M. (2002). Intentional Social Action in Virtual Communities. Journal of Interactive Marketing, 16(2), 2-21.

Bandura, A. (1977). Social Learning Theory. Englewood Cliffs, NJ: Prentice Hall.

Bernoff, J., \& Li, C. (2008). Harnessing the power of the ohso-social web. MIT Sloan Management Review, 49(3), 36-42.

Bilgihan, A., Peng, C., \& Kandampully, J. (2014). Generation Y's dining information seeking and sharing behavior on social networking sites. International Journal of Contemporary Hospitality Management, 26(3), 349-366.

Bonabeau, E. (2004). The perils of the imitation age. Harvard Business Review, 82(6), 45-54.

Boyd, D. M., \& Ellison, N. B. (2007). Social Network Sites: Definition, History, and Scholarship. Journal of Computer-Mediated Communication, 13(1), 201- 230.

Cheung, C. M., Xiao, B. S., \& Liu, I. L. (2014). Do Actions Speak Louder than Voices? The Signaling Role of Social Information Cues in Inflencing Consumer Purchase Decisions. Decision Support Systems, $65,50-58$.

Chu, S. C., \& Choi, S. M. (2011). Electronic word-ofmouth in social networking sites: a crosscultural study of the united states and china. Journal of Global Marketing, 24(3), 263-281. 
Chu, S.-C., \& Kim, Y. (2011). Determinants of consumer engagement in electronic word-of-mouth (eWOM) in social networking sites. International Journal of Advertising: The Review of Marketing Communications, 30(1), 47-75.

Cobb, S. (1976). Social support as a moderator of life stress. Psychosomatic Medicine, 38(5), 300-314. Do-Hyung, P., Jumin, L., \& Ingoo, H. (2007). The effect of on-line consumer reviews on consumer purchasing intention: the moderating role of involvement. International Journal of Electronic Commerce, 11(4), 125-148.

Engel, J. F., Kollat, D. T., \& Blackwell, R. D. (1968). Consumer Behavior. New York: Holt, Rinehart and Winston, Inc.

Forman, C., Ghose, A., \& Wiesenfeld, B. (2008). Examining the Relationship Between Reviews and Sales: The Role of Reviewer Identity Disclosure in Electronic Markets. Information Systems Research, 19(3), 291-313.

Fotis, J., Buhalis, D., \& Rossides, N. (2012). Social Media Use and Impact during the Holiday Travel Planning Process (pp 13-24). Spinger-Verlag.

Foxall, G. (2005). Understanding the Consumer Choice. Palgrave Macmillan.

Goh, K. Y., Heng, C. S., \& Lin, Z. (2013). Social Media Brand Community and Consumer Behavior: Quantifying the Relative Impact of User- and Marketer-Generated Content. Information Systems Research, 24(1), 88-107.

Hajli, M. (2012). An integrated model for e-commerce adoption at the customer level with the impact of social commerce. International Journal of Information Science and Management, 16, 77-97.

Hajli, N. (2015). Social commerce constructs and consumer's intention to buy. International Journal of Information Management, 35(2), 183-191.

Hajli, N., Lin, X., Featherman, M., \& Wang, Y. (2014). Social Word of Mouth: How Trust Develops in the Market. International Journal of Market Research, 56(5), 673-689.

Han, B. O., \& Windsor, J. (2011). User's willingness to pay on social network sites. Journal of Computer Information Systems, 51(4), 31-40.

Heinrichs, J. H., Lim, J. S., \& Lim, K. S. (2011). Influence of social networking site and user access method on social media evaluation. Journal of Consumer Behaviour, 10(1), 347-355. 
Hennig-Thurau, T., Gwinner, K. P., Walsh, G., \& Gremler, D. D. (2004). Electronic word-of-mouth via consumer-opinion platforms: What motivates consumers to articulate themselves on the Internet? Journal of Interactive Marketing, 18(1), 38-52.

Hennig-Thurau, T., Malthouse, E. C., Friege, C., Gensler, S., Lobschat, L., Rangaswamy, A., \& Skiera, B. (2010). The Impact of New Media on Customer Relationships. Journal of Service Research, 13(3), 311-330.

Hennig-Thurau, T., Wiertz, C., \& Feldhaus, F. (2012). Exploring the "Twitter Effect:" An Investigation of the Impact of Microblogging Word of Mouth on Consumers' Early Adoption of New Products. Available at SSRN, 2016548.

Huang, Z., \& Benyoucef, M. (2013). From e-commerce to social commerce: A close look at design features. Electronic Commerce Research and Applications, 12(4), 246-259.

Kaplan, A. M., \& Haenlein, M. (2010). Users of the world, unite! The challenges and opportunities of Social Media. Business Horizons, 53(1), 59-68.

Kotler, P., \& Armstrong, G. (2016). Principles of Marketing (16 ed.). NJ: Prentice-Hall. [34] Kotler, P., \& Keller, K. L. (2016). Marketing Management (15 ed.). NJ: Prentice-Hall.

Kwahk, K.-Y., \& Ge , X. (2012). The Effects of Social Media on E-commerce: A Perspective of Social Impact Theory. 45th Hawaii International Conference on System Sciences, pp. 1814-1823.

Li, D. C. (2011). Online Social Network Acceptance: A Social Perspective. Internet Research, 21(5), 562580.

Liang, T.-P., \& Turban, E. (2011). Introduction to the the Special Issue Social Commerce: A Research Framework for Social Commerce. International Journal of Electronic Commerce, 16(2), 5-13.

Liang, T.-P., Ho, Y.-T., Li, Y.-W., \& Turban, E. (2011). What Drives Social Commerce: The Role of Social Support and Relationship Quality. International Journal of Electronic Commerce, 16(2), 69-90.

Mohana, S., Sun, S., Amidi, A., Khani, F., \& Khani, F. (2016). The applications of social commerce constructs. International Journal of Information Management, 36(3), 425-432.

$\mathrm{Ng}$, C. S.-P. (2013). Intention to purchase on social commerce websites across cultures: A cross-regional study. Information \& Management, 50(8), 609-620.

Nicosia, F. M. (1966). Consumer decision processes : marketing and advertising implications. Englewood Cliffs, N.J: Prentice-Hall. 
Osei, B. A., \& Abenyin, A. N. (2016). Applying the EngellKollat-Blackwell model in understanding international tourists' use of social media for travel decision to ghana. Information Technology and Tourism, 16(3), 1-20.

Pan, B., MacLaurin, T., \& Crotts, J. (2007). Travel blogs and the implications for destination marketing. Journal of Travel Research, 46(1), 35-45. [44] Park, C., \& Lee, T. M. (2009). Information direction, website reputation and eWOM effect: A moderating role of product type. Journal of Business Research, 62(1), 61-67.

Power, D. J., \& Phillips-Wren, G. (2011). Impact of Social Media and Web 2.0 on Decision-Making. Journal of Decision System, 20(3), 249-261.

Rad, A. A., \& Benyoucef, M. (2011). A model for understanding social commerce. Journal of Information Systems Applied Research, 4(2), 63-73.

Rice, C. (1993). Consumer Behaviour: Behavioural Aspects of Marketing. Boston: Oxford.

Ridings , C. M., \& Gefen, D. (2004). Virtual Community Attraction: Why People Hang Out Online. Journal of Computer-Mediated Communication, 10(1), 00-00.

Schiffman, L. G., \& Wisenblit, J. (2015). Consumer Behavior (11 ed.). NJ: Prentice-Hall.

Senecal, S., \& Nantel, J. (2004). The influence of online product recommendations on consumers' online choices. Journal of Retailing, 80(2), 159-169.

Simpson, P. M., Siguaw, J. A., \& Cadogan, J. W. (2008). Understanding the consumer propensity to observe. European Journal of Marketing, 42(1/2), 196-221.

Song, S., \& Yoo, M. (2016). The role of social media during the pre-purchasing stage. Journal of Hospitality and Tourism Technology, 7(1), 84-99.

Statista. (2016, September 02). Global social networks ranked by number of users 2016. Retrieved Spetember 10, 2016, from Statista: http://www.statista.com/statistics/272014/globalsocial-networksranked-by-number-of-users/

Statistic Brain. (2016, August 01). Facebook Statistics. Retrieved September 12, 2016, from Statistic Brain: http://www.statisticbrain.com/facebook-statistics/

Stephen, A. T., \& Galak, J. (2012). The Effects of Traditional and Social Earned Media on Sales: A Study of a Microlending Marketplace. Journal of Marketing Research, 49(5), 624-639.

Tyagi, C. L., \& Kumar, A. (2004). Consumer Behaviour. US: Atlantic Publishers. 
Wang, J.-C., \& Chang, C.-H. (2013). How online social ties and product-related risks influence purchase intentions: A Facebook experiment. Electronic Commerce Research and Applications, 12(5), 337- 346. Wang, X., Yu, C., \& Wei, Y. (2012). Social Media Peer Communication and Impacts on Purchase Intentions: A Consumer Socialization Framework. Journal of Interactive Marketing, 26(4), 198-208.

Wang, Y., \& Yu, C. (2015). Social interaction-based consumer decision-making model in social commerce: The role of word of mouth and observational learning. International Journal of Information Management.

Xiang, Z., \& Gretzel, U. (2010). Role of social media in online travel information search. Tourism Management, 31(2), 179-188.

Yadav, M. S., de Valck, C., Hennig-Thurau, T., Hoffman, D. L., \& Spann, M. (2013). Social Commerce: A Contingency Framework for Assessing Marketing Potential. Journal of Interactive Marketing, 27(4), 311-323.

Yubo, C., \& Jinhong , X. (2005). Third-party product review and firm marketing strategy. Marketing Science, 24(2), 218-240.

Zhang, H., Lu, Y., Gupta, S., \& Zhao, L. (2014). What motivates customers to participate in social commerce? The impact of technological environments and virtual customer experiences. Information $\&$ Management, 51(8), 1017-1030.

Zhang, K. Z., \& Benyoucef, M. (2016). Consumer Behavior in Social Commerce: A Literature Review. Decision Support Systems, 86, 95-108.

Zhou, L., Zhang, P., \& Zimmermann, H.-D. (2013). Social commerce research: An integrated view. Electronic Commerce Research and Applications, 12(2), 61-68. 
